\section{Value of booster immunisation with influenza vaccine in patients undergoing haemodialysis}

The public health authorities of most Western countries recommend annual influenza vaccination for some patients, including those with end stage renal disease. ${ }^{1}$ Patients on haemodialysis, however, show impaired antibody responses after a single influenza vaccination, which may result in insufficient protection. ${ }^{2}$ These patients also respond poorly to hepatitis $B$ vaccine, but a booster immunisation will produce protective antibody titres. ${ }^{3}$ In a large group of patients on haemodialysis we therefore attempted to induce adequate protection against influenza by performing a booster vaccination.

\section{Patients, methods, and results}

Ninety eight patients in a stable condition who were undergoing long term intermittent haemodialysis took part. They were aged 17 to 76 (median 57) years and had been undergoing haemodialysis for one month to 13 years (median two years). None had received steroids or immunosuppressive drugs for at least six months. Twenty nine healthy volunteers aged 19 to 69 (median 27) years served as controls. A commercially available trivalent split virus vaccine (Alorbat, Asta Werken, Bielefeld, Federal Republic of Germany) containing $15 \mu \mathrm{g}$ haemagglutinin of A/Philippines/2/82 $\left(\mathrm{H}_{3} \mathrm{~N}_{2}\right)$, A/Chile/1/83 $\left(\mathrm{H}_{1} \mathrm{~N}_{1}\right)$, and $\mathrm{B} / \mathrm{USSR} / 100 / 83$ was administered by intramuscular injection in the upper arm on day 0 and day 30 (booster immunisation). Serum was obtained on days 0,30 , and 60 . The study took place in the autumn of 1985 . Antibody titres were determined twice in paired sera by the haemagglutination inhibition technique, and geometric mean titres were calculated. A fourfold or more rise in titre was considered to be a satisfactory response, and protection was defined by titres of $\geqslant 100$ against influenza $A$ and $\geqslant 200$ against ether treated influenza $B .{ }^{4}$

Before vaccination geometric mean titres against the three virus strains did not differ between the groups (table). After the first injection the patients undergoing dialysis had significantly lower geometric mean titres than the controls for all viruses tested $(\mathbf{p}<0.001$, Wilcoxon rank test). Booster vaccination did not influence the final titres reached.

Among the initially unprotected patients and controls significantly fewer of the patients showed a more than fourfold rise in titre against the three viruses $\left(\mathrm{H}_{3} \mathrm{~N}_{2}\right.$ and $\mathrm{B} \mathrm{p}<0.05, \mathrm{H}_{1} \mathrm{~N}_{1} \mathrm{p}<0.001 ; \chi^{2}$ test) after the first injection (table). Booster immunisation produced greater than fourfold rises in titres against $\mathrm{H}_{3} \mathrm{~N}_{2}, \mathrm{H}_{1} \mathrm{~N}_{1}$, and $B$ in, respectively, a further $14 \%, 8 \%$, and $0 \%$ of the patients and $5 \%, 8 \%$, and $4 \%$ of the controls. The seroconversion rate to protective titres against $\mathrm{H}_{3} \mathrm{~N}_{2}$ and B was also significantly lower among the patients after the first injection than among the controls $\left(p<0.001, \chi^{2}\right.$ test). Booster immunisation increased the seroconversion rate among the patients but not significantly so. Together the first and second vaccinations induced adequate protective antibody titres in $81(83 \%)$ of the patients for $\mathrm{H}_{3} \mathrm{~N}_{2}, 37(38 \%)$ for $\mathrm{H}_{1} \mathrm{~N}_{1}$, and $47(48 \%)$ for $B$. The statistical significance of the results measured as geometric mean titres, more than fourfold rises in titres, and seroconversion rates was maintained when controls were compared with age and sex matched patients undergoing dialysis.

\section{Comment}

In patients undergoing haemodialysis vaccination with an influenza vaccine was significantly less effective than in the controls for all three

Effects of first injection and booster vaccination with influenza vaccine on mean log geometric mean titre against influenza viruses $\mathrm{H}_{3} \mathrm{~N}_{2}, \mathrm{H}_{1} \mathrm{~N}_{1}$, and $B$ in patients undergoing haemodialysis and controls, and greater than fourfold rises in titres and seroconversion rates to protective titres in individuals with unprotective prevaccination titres

\begin{tabular}{|c|c|c|c|c|c|c|}
\hline & \multicolumn{3}{|c|}{ Patients ( $n=98$ ) } & \multicolumn{3}{|c|}{ Controls $(n=29)$} \\
\hline & $\mathrm{H}_{3} \mathbf{N}_{2}$ & $\mathrm{H}_{1} \mathrm{~N}_{1}$ & B & $\mathrm{H}_{3} \mathrm{~N}_{2}$ & $\mathrm{H}_{1} \mathrm{~N}_{1}$ & B \\
\hline $\begin{array}{l}\text { Mean log geometric mean titre: } \\
\text { Before first injection } \\
\text { After first injection } \\
\text { After booster vaccination }\end{array}$ & $\begin{array}{l}1 \cdot 10 \\
2 \cdot 21 \\
2 \cdot 30\end{array}$ & $\begin{array}{l}1.07 \\
1.66 \\
1.68\end{array}$ & $\begin{array}{l}1 \cdot 28 \\
2.05 \\
2.05\end{array}$ & $\begin{array}{l}1 \cdot 14 \\
2 \cdot 93 \\
3 \cdot 01\end{array}$ & $\begin{array}{l}1 \cdot 12 \\
2 \cdot 39 \\
2 \cdot 47\end{array}$ & $\begin{array}{l}1 \cdot 14 \\
2 \cdot 63 \\
2 \cdot 62\end{array}$ \\
\hline $\begin{array}{l}\text { No (\%) with non-protective titres } \\
\text { before vaccination } \\
\text { No }(\%) \text { with } \geqslant \text { fourfold rise in titre: }\end{array}$ & $71(72)$ & $88(90)$ & $82(84)$ & $20(69)$ & $25(86)$ & $25(86)$ \\
\hline $\begin{array}{l}\text { After first injection } \\
\text { After second injection } \\
\text { Seroconversion rate (No }(\%)) \text { : }\end{array}$ & $\begin{array}{l}49(69) \\
59(83)\end{array}$ & $\begin{array}{l}39(44) \\
46(52)\end{array}$ & $\begin{array}{l}47(57) \\
47(57)\end{array}$ & $\begin{array}{l}19(95) \\
20(100)\end{array}$ & $\begin{array}{l}21(84) \\
23(92)\end{array}$ & $\begin{array}{l}20(80) \\
21(84)\end{array}$ \\
\hline $\begin{array}{l}\text { After first injection } \\
\text { After booster vaccination }\end{array}$ & $\begin{array}{l}47(66) \\
54(76)\end{array}$ & $\begin{array}{l}22(25) \\
27(31)\end{array}$ & $\begin{array}{l}22(27) \\
31(38)\end{array}$ & $\begin{array}{l}17(85) \\
18(90)\end{array}$ & $\begin{array}{l}21(84) \\
22(88)\end{array}$ & $\begin{array}{l}19(76) \\
20(80)\end{array}$ \\
\hline
\end{tabular}

viruses. The better conversion rate to protective titres against $\mathrm{H}_{3} \mathrm{~N}_{2}$ in patients can be explained by a "priming" effect, as the $\mathrm{H}_{3} \mathrm{~N}_{2}$ strains haye circulated for over 10 years and have caused several epidemics in the Netherlands. Booster immunisation only marginally improved the efficapy of vaccination against the three influenza viruses in both the patients and the controls. Only a small minority of the 98 patients developed protective tites as a result of the second immunisation: seven for $\mathrm{H}_{3} \mathrm{~N}_{2}$, five for $\mathrm{H}_{1} \mathrm{~N}_{1}$, and nine for $\mathrm{B}$. Therefore we cannot recommend a booster immunisation wh influenza vaccine in patients undergoing dialysis. Prophylactic amantadife therapy, which protects against influenza $A$ viruses but not against influerga $\mathrm{B}$, may be considered for these patients if an epidemic is imminent.

This study was supported by the Artificial Kidney Foundation of the St Clai Hospital, Rotterdam, The Netherlands.

1 Eickhoff ThC. Immunization against influenza: rationale and recommendations. $\mathcal{F}$ Infect $\vec{\oplus}$ 1971;123:446-54.

2 Versluis DJ, Beyer WEP, Masurel N, Weimar W. Influenza vaccination in dialysis and transp patients. Antiviral Res 1985;5(suppl 1):289-92.

3 Desmyter J, Colaert J, de Groote G, et al. Efficacy of heat inactivated hepatitis B vaccine haemodialysis patients and staff. Lancet 1983;ii:1323-8.

4 Masurel N, Laufer J. A one year study of trivalent influenza vaccine in primed and unprime. volunteers: immunogenicity, clinical reactions and protection. $f$ Hyg (Camb) 1984;92:263-7\%

5 Monto AS, Gunn RA, Bandyk MG, et al. Prevention of Russian influenza by amantadine. JA 1979;241:1003-7.

University Hospital Rotterdam-Dijkzigt, 3015 GD Rotterdam, The Netherlands

D J VERSLUIS, MD, senior resident internal medicine

W E P BEYER, MD, virologist

N MASUREL, MD, professor of virology

W WEIMAR, MD, senior registrar internal medicine

St Clara Hospital, Rotterdam, The Netherlands

P KRAMER, MD, nephrologist

St Franciscus Hospital, Rotterdam, The Netherlands PH P N M DIDERICH, MD, nephrologist

Correspondence to: Dr Versluis.

\section{Neuropathy of the feet due to running $0 \overrightarrow{\mathrm{B}}$ cold surfaces}

After running a race in bare feet on a day when the temperature was bela freezing several runners presented to hospital with injuries to their feet. Such injuries have not been reported before.

\section{Patients and findings}

In February 1986, 160 runners took part in a sponsored five mile run; all had run in bare feet. The participants were members of a karate club, and mostnof them had run in bare feet on previous occasions without any problems. TTe course was along paths in a park in Leicester; at the start of the race the ambiext temperature was $-5^{\circ} \mathrm{C}$ and the ground temperature $-9^{\circ} \mathrm{C}$ (United Kingdig Meteorological Office, personal communication). All the runners finished the event without any problems. Shortly afterwards, however, 25 participanin presented to the accident and emergency department with almost identifos njuries to their feet.

All the patients complained of severe pain in their feet, which had developed shortly after they finished the race. On examination the weightbearing surface the soles of their feet were bright red and deeply ingrained with dirt. The areas affected resembled partial thickness burns. Large tense blisters were also found in several patients; debridement of these showed partial thickness skin log (figure).

\section{Comment}

Most of the patients had taken part in similar runs before but never on freezing day. In the past they had experienced pain in their feet during run and on finding blistering had stopped. On this particular day pain had been absent during the event and the skin damage had not become appare until some time afterwards. 


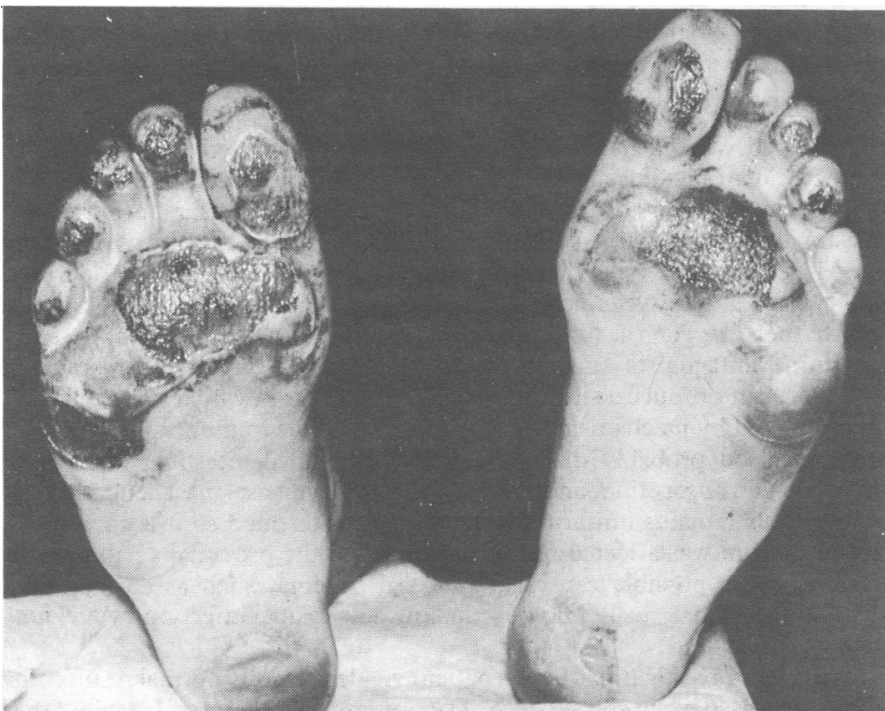

Partial thickness loss of skin on feet.

Although this problem has not been described before in runners, experimental and clinical studies have shown that nerve conduction is altered by cooling. Ungley $e t$ al looked at the symptoms experienced by naval staff during the second world war after immersion of their feet in cold sea water: all the subjects reported loss of sensation.' Sinclair $e t$ al showed that cooling of the legs results in, firstly, cold feet, then pain, then loss of sensation to touch. ${ }^{2}$ In a more recent study Basbaum cooled the sciatic nerve of a rat and found that a reduction in the temperature of the nerve to $5^{\circ} \mathrm{C}$ resulted in a total block in conduction, which recovered on warming. ${ }^{3}$

It is likely that because of the low ground temperature $\left(-9^{\circ} \mathrm{C}\right)$ the runners reported on here developed temporary neuropathy of the feet, lost all sensation, and were able to continue running despite the severity of their injuries. This indicates the dangers of running on cold surfaces without adequate footware.

1 Ungley CC, Channell GD, Richards RL. Immersion foot syndrome. Brf Sirg 1945;33:17-31. 2 Sinclair DC, Hinshaw JR. Sensory changes in nerve blocks induced by cooling. Brain 1951;74 318-35.

3 Basbaum CB. Induced hypothermia in peripheral nerve: electron microscopic and electrophysiological observations. $\mathcal{F}$ Neurocyrol 1973;2:171-87.

(Accepted 28 October 1986)

Leicester Royal Infirmary, Leicester LE1 5WW

M REICHL, FRCSED, accident and emergency registrar

\section{Occult chlamydial ophthalmia in men with non-gonococcal urethritis}

Chlamydial ophthalmia in adults usually results from autoinnoculation with genital secretion containing Chlamydia trachomatis (D-K). ${ }^{12}$ Little is known about the relation between occult chlamydial ophthalmia and overt genitourinary infections. The recent introduction of fluorescein labelled monoclonal antibody allows rapid and reliable identification of chlamydia in conjunctival smears. ${ }^{3}$ We used this method in a prospective study to evaluate the prevalence of chlamydia in the eye in men with urethritis associated with chlamydia.

\section{Patients, methods, and results}

Informed consent to ophthalmological assessment was given by 60 out of 67 men with non-gonococcal urethritis who presented consecutively to the department of genitourinary medicine. The patients' eyes were examined by slit lamp for conjunctival papillas and follicles, corneal staining, and opacities. Papillas and follicles in both eyes were graded on a four point scale. ${ }^{4}$

Topical amethocaine $1 \%$ was instilled in both eyes, and after five minutes conjunctival scrapings were taken with a scalpel blade, smeared on to a microscope slide, and fixed with methanol. Smears were stained with Orion Chlamyset fluorescein labelled monoclonal antibody and the fluorescent chlamydial inclusion bodies counted $C$ trachomatis was isolated from urethral swabs by innoculation on to McCoy cell monolayers treated with idoxuridine. The data were analysed by $\chi^{2}$ (with Yates's correction), Student's $t$ test, and analysis of variance (one way).

Eight of the 60 men had asymptomatic chlamydial ophthalmia; none had punctate keratitis, pannus, or tarsal scarring. Conjunctival smears showed five to 10 inclusion bodies in five men and 10-50 in the remaining three. Six of the eight men had evidence of genital infection associated with chlamydia as indicated by isolation of chlamydia either in the man or in his consort. There were no significant demographic or clinical differences between those who had chlamydia in the eye and those who did not (table). The eye disease was apparently cured by conventional treatment with oral triple tetracycline (tetracycline, chlortetracycline, and demeclocycline; Deteclo) for two weeks.

Epidemiological and clinical features of men with non-gonococcal urethritis

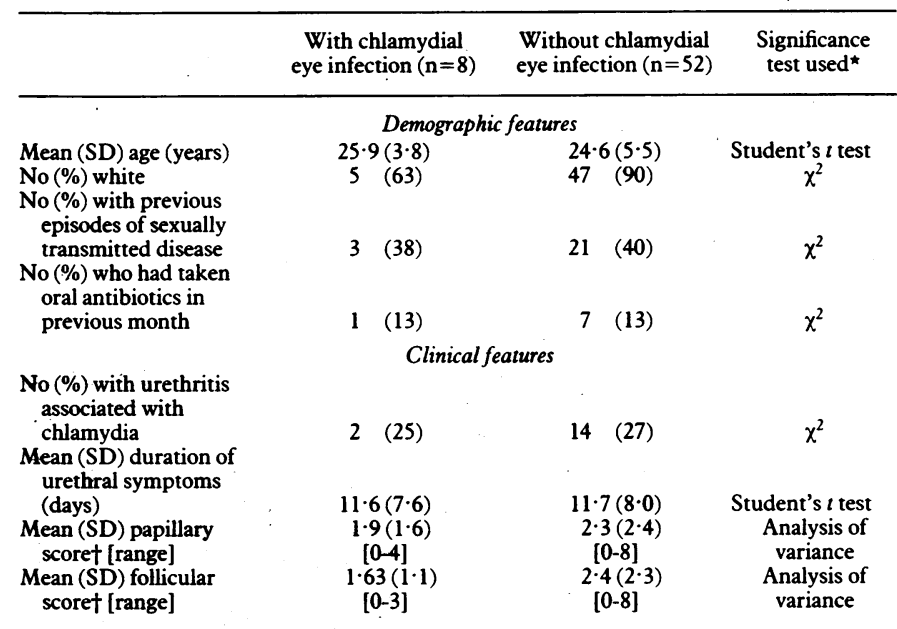

*All differences in variables between groups not significant.

† Sum of grades of papillas or follicles on upper and lower eyelids in both eyes $(0=$ none, $1=$ mild, $2=$ moderate, $3=$ severe; maximum score $=12$ ).

\section{Comment}

Asymptomatic chlamydial eye infection in men with non-gonococcal urethritis has not been described previously; indeed, in Sweden a study of cultures failed to identify any cases of chlamydial eye infection in $\mathbf{8 5 5}$ unselected patients attending a clinic for sexually transmitted diseases, even though $18 \cdot 6 \%$ had genital chlamydia. ${ }^{5}$ In our study those patients who had chlamydia in the eye had few inclusion bodies. We postulate that the technique of conjunctival scraping combined with use of a specific monoclonal antibody to detect $C$ trachomatis is more sensitive than smears and conventional tissue culture. The minor conjunctival changes seen, predominantly papillas and follicles, were common and did not distinguish clinically between those who did and did not have chlamydial eye infection. This parallels the well recognised occult nature of chlamydial infection of the genital tract.

This study shows that chlamydial eye disease may be asymptomatic and is not uncommon in men with non-gonococcal urethritis. Further studies are necessary to document the clinical course of this condition and its response to concurrent treatment of urethritis associated with chlamydia.

1 Viswalingam ND, Wishart MS, Woodland RM. Adult chlamydial ophthalmia. Br Med Bull 1983;39:123-7.

2 Dunlop EMC Jones BR, Al Hussaini MK. Genital infection in association with TRIC virus infection of the eye. Br $\mathcal{F}$ Vener Dis 1964;40:33-42.

3 Hawkins DA, Wilson RS, Thomas BJ, Evans RT. Rapid, reliable diagnosis of chlamydial ophthalmia by means of monoclonal antibodies. Brf Ophthalmol 1985;69:640-4.

4 Dawson CR, Jones BR, Darougar S. Blinding and non blinding trachoma, the assessment of intensity of upper tarsal inflammatory disease and blinding lesions. Bull WHO 1975;52:279-82.

5 Ronnerstam R, Persson K, Hansson H, Renmarker K. Prevalence of chlamydial eye infections in patients attending an eye clinic, a VD clinic and in healthy persons. $\mathrm{Br} \mathcal{J}$ Ophthalmol 1985;69:385-8.

(Accepted 21 October 1986)

Department of Genitourinary Medicine and Ophthalmology, Royal Hallamshire Hospital, Sheffield S10 2JF

E F MONTEIRO, MRCP, senior registrar in genitourinary medicine

J A BRADBURY, FRCS, registrar in ophthalmology

M O'DONNELL, FRCS, registrar in ophthalmology

I G RENNIE, FRCS, senior lecturer in ophthalmology

G R KINGHORN, MD, MRCP, consultant in genitourinary medicine

Correspondence to: Dr Monteiro. 